\title{
Research on the Interactive Development of Innovation and Entrepreneurship Education and Tourism Specialty Education in the Context of Cultural and Tourism Integration: A Case Study on the Production of Ubiquitous Learning Space in YXHMC
}

\author{
Ping Zhao ${ }^{\mathrm{a}}$, Jiaonan $\mathrm{Li}^{\mathrm{b}}$, Xiaoyan Zhang ${ }^{\mathrm{c}}$ \\ Yinxing Hospitality Management College of CUIT, Chengdu 611743, China \\ azhaoping@yxhmc.edu.cn, blijiaonan@yxhmc.edu.cn, 'zhangxiaoyan_lyx@yxhmc.edu.cn
}

\begin{abstract}
The main objective of this study is to design an interactive development model of innovation \& entrepreneurship education and tourism specialty education under the background of the culture and tourism integration, so as to fully explore the potential of students' innovation \& entrepreneurship in culture and tourism industry, and then innovate the talents training mode to improve the effect of tourism specialty education. A conceptual model was developed to show a three-dimensional system of ubiquitous learning space which is a practical way for interactive development of innovation \& entrepreneurship education and tourism specialty education. The case of YXHMC shows that in the interactive development of innovation \& entrepreneurship education and tourism specialty education, it is the foundation to break through the traditional mode and build creative and innovative teaching space, the key is to integrate resources to build innovation \& entrepreneurship resources sharing space, and the guarantee of interactive development is to multidimensional interact and link the education space inside and outside the college.
\end{abstract}

Keywords: Cultural and tourism integration; innovation \& entrepreneurship; tourism specialty education; ubiquitous learning space.

\section{Introduction}

The implementation of innovation \& entrepreneurship education is not only the need of national innovation driven development strategy, but also the need of improving the quality of higher education. China's tourism industry has entered a new stage, facing the demand of higher security, more choices, higher quality services and higher satisfaction. At present, new business forms of culture and tourism are constantly emerging, such as culture and tourism characteristic town, maker base, agricultural theme park, rural leisure complex, historical ancient town, historic district, etc. The tourism industry gone through industrialization, intelligence, Internet and holistic stage, and will stepping into a culture revolution. Culture and tourism are a new mode of tertiary industry which is strongly supported by government, and the critical factors are capital, technology and talents, in which talents are the scarcest. In order to promote tourism with culture and highlight culture with tourism, it is urgent to train a group of professionals who can grasp the characteristics and pattern of cultural and tourism development and have innovative consciousness. The multi-disciplinary interdisciplinary nature of tourism specialty education becomes more prominent during the integration of cultural and tourism. It is urgent for tourism specialty education to focus on the construction of innovation ability, improve the comprehensive quality of industrial chain, and precisely grasp the characteristics and pattern of culture and tourism.

The interactive development of innovation \& entrepreneurship education and tourism specialty education is essential to cultivate high-level professional and technical talents in culture and tourism industry, such as hotel management talents, tourist destination or scenic spot management talents, travel agency management (marketing) talents, tour guide talents, tourism media talents, self-driving talents, tourism talents in ethnic areas, tourism targeted poverty alleviation talents, rural tourism entrepreneurship talents and so on. The paper constructs a ubiquitous learning space, provides a new perspective for the interactive development of innovation \& entrepreneurship education and tourism 
specialty education, and raises the tourism specialty education from the theoretical level of teaching reform to the practical level of path and method, which is a new and innovative research.

The paper proposes to build a three-dimensional system of ubiquitous learning space through break through the traditional mode and build creative and innovative teaching space, integrate resources to build innovation \& entrepreneurship resources sharing space, multidimensional interact and link the education space inside and outside the college, so as to realize the interactive development of innovation \& entrepreneurship education and tourism specialty education. Taking the integration of culture and tourism as the starting point, the paper makes a comprehensive and systematic theoretical and empirical study on the interactive development approaches and methods of innovation \& entrepreneurship education and tourism specialty education, reflecting a new perspective. The paper has a strong problem orientation and practical pertinence dedicating to explore the potential of students' innovation \& entrepreneurship in culture and tourism industry.

\section{Interactive Development of Innovation \& Entrepreneurship Education and Tourism Specialty Education}

\subsection{The Main Issue}

With the rapid development of China's tourism industry, it is difficult for the traditional tourism specialty education to meet the diversified needs of culture and tourism industry. The contribution of tourism to promoting national happiness, social harmony and international peace and stability has attracted more attention at present, thus, the strategic position of tourism industry has become increasingly prominent. More than 30 provinces and districts or cities have prioritized culture and tourism as a strategic pillar industry or a leading industry, and issued a series of policies and measures to promote the development. The transformation of tourism requires the improvement of quality and quantity of tourism practitioners for tourism specialty education partly due to the supply side structural reform provides more opportunities. At present, the quantity and quality of tourism sspecialty education in China cannot meet the actual needs, which has become a bottleneck restricting the high-quality development of culture and tourism industry.

The demand for senior skilled talents in culture and tourism industry is huge, and the structural contradiction between tourism supply and demand is prominent. The integrated development of culture and tourism must be based on the cultivation of talents, which requires tourism specialty education should be centered on capacity building urgently. Innovation ability was highlighted in the Opinions on Deepening the Reform of Education System and Mechanism issued by the state council on September 24, 2017. The integration development of culture and tourism calls for innovation to drive new vitality, then being good at innovation in service and management practice has become one of the characteristics of high-quality talents in culture and tourism industry. The characteristics of tourism public consumption, social concern and industrial chain integration determine the importance of innovation. The improvement of innovation ability is closely related to the knowledge structure of talents, which mainly through professional education in colleges and universities. The innovation \& entrepreneurship education of college students is one of the main ways to tap students' innovation potential and optimize the theoretical knowledge structure. However, there is a structural supply and demand dislocation between talents training and tourism industry. The tourism specialty education cannot respond to the changes in demand and match new business forms timely, and it is difficult to cultivate open, compound and innovative high-quality tourism professionals.

\subsection{Practicable Way for Interactive Development of Innovation \& Entrepreneurship Education and Tourism Specialty Education}

According to L. Steinhaus's Process Model theory (An Introduction to Curriculum Research and Development, 1975), in the innovation \& entrepreneurship education of college students, we should pay more attention to the way of education rather than the content of education, and emphasize how 
students learn non teachers how to teach. Therefore, we should encourage students to actively participate in innovation \& entrepreneurship, finally help students to develop their creativity.

With the rapid development of digital society, tourism professional learning will no longer only take place in the college, no longer limited to classroom, laboratory, playground, library and other physical places (Wang, 2017). Students' acquisition of knowledge and improvement of innovation \& entrepreneurship ability are realized in a large number of practical activities. Therefore, the interactive development mode of innovation \& entrepreneurship education and tourism specialty education is to build a three-dimensional system of ubiquitous learning space through break through the traditional mode and build creative and innovative teaching space, integrate resources to build innovation $\&$ entrepreneurship resources sharing space, multidimensional interact and link the education space inside and outside the college. At last, realize the goal of fully supporting students' personalized learning, cultivating students' innovative thinking development, expanding students' professional vision of culture and tourism, and stimulating the potential of innovation \& Entrepreneurship.

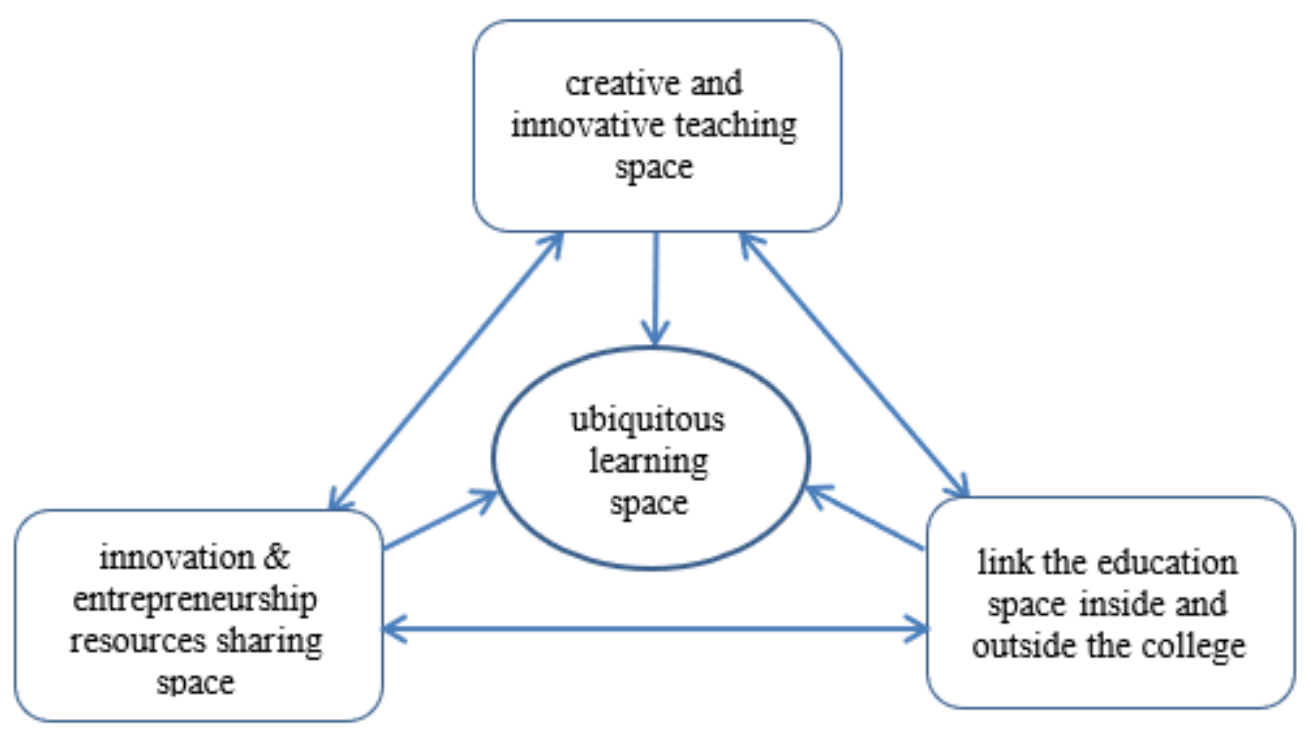

Fig.1 Conceptual Model of three-dimensional system of ubiquitous learning space

\subsubsection{Break through the Traditional Mode and Build Creative and Innovative Teaching Space}

It is the foundation to break through the limitations of physical learning space in the college, and provide a multi-dimensional learning environment in the process of tourism specialty education according to the concept of integration of culture and tourism. Through the comprehensive reform of teaching content, course system, practice link, teaching operation and management mechanism, teaching organization form, YXHMC break through the traditional mode and create creative and innovative teaching space.

\subsubsection{Student Centered Heuristic Teaching}

YXHMC carries out diversified teaching method reform and innovation, which takes employment as the guide and vocational ability training as the center, formulated a professional training program conducive to the cultivation of applied, compound and innovative talents. YXHMC carries out teaching reform and curriculum construction, undertakes a number of provincial education reform projects, builds provincial and college level sharing courses, and develops new courses needed by the industry. The curriculum emphasizes the training of operation skills, increases the number of hours of practical courses, and requires that all courses must design the guidance scheme of practical teaching content. The students' comprehensive quality has been improved through the one calendar and multiple certificates training approach, expands students' innovation \& Entrepreneurship skills and obtains various training skill certificates recognized by the state, society and industry. 


\subsubsection{Open Teaching}

Sichuan is building a strong culture and tourism province to realize the transformation and upgrading of traditional tourism. In accordance with the strategic deployment of Sichuan to build a regional coordinated development pattern of one trunk with multiple branches and five areas in coordination, YXHMC actively meets the needs of culture and tourism industry and innovation chain, and establishes a culture and tourism industry chain business module with higher technology content and stronger capability requirements. The open teaching mode of in class and out of class, in college and out of college guided by ability training have been implemented. In class and in college learning is the main way for students to acquire knowledge and establish thinking system. Out of class and out of college learning play an important role in the cultivation of students' comprehensive quality, innovative spirit and practical ability. For example, YXHMC has carried out a lot of work in tourism poverty alleviation in recent years, which not only broadens students' vision, but also provides many practical opportunities for students. Students have chosen their hometown as the research object to write graduation theses on tourism poverty alleviation, rural tourism industry development, tourism product design and other topics, and offer suggestions for poverty alleviation in their hometown, such as: Research on the Current Situation and Countermeasures of Tourism Poverty Alleviation in Xijie Town, Research on Rural Tourism Product Development in Yuechi County, Guang'an City, Research on Yibin Liangjiang Rural Tourism Development Strategy, etc.

\subsubsection{Project Based Teaching}

According to the target of application-oriented, combined with the foundation and characteristics of college, HYMC develops tourism specialty education programs in combination with industrial enterprises, which focus on the content adjustment from the perspective of tourism discipline construction and training target to different levels of talents. One way is to select the skill courses to implement the project-based teaching relying on the project of teachers serving the society. According to the curriculum in the tourism specialty education program, students are encouraged to participate in practical projects to stimulate students' interest and potential, and cultivate students' team cooperation and innovation ability. The second is to combine the studio and project with some courses, students simulate the operation of practical projects in the studio, and integrate the possible innovation $\&$ entrepreneurship into the future career development according to the development needs of the tourism industry and their own interests.

\subsubsection{Integrate Resources to Build Innovation \& Entrepreneurship Resources Sharing Space}

The integrated development of culture and tourism makes the tourism industry more extensive, and there is a shortage of talents who have strong innovation and creativity ability and can integrate and integrate knowledge in various related fields. YXHMC cooperates with enterprises in tourism route design, educational tourism, self-driving tourism and other fields, build a shared space of educational resources through multi-dimensional interaction with tourism industry and enterprises, and break through the barrier between specialty education and students' entrepreneurship. Meanwhile, integrate the teachers and subject education resources of exhibition economy and management and cultural industry management, the simulation operation of practical projects stimulates the students' interest and potential of innovation and entrepreneurship, emerge outstanding makers (students major in tourism management) such as Ling Dai, Yuanbo Tuo, Yuemao Li, etc.

\subsubsection{Promote Competition and Create a Soil for Innovation \& Entrepreneurship}

At present, new business forms of culture and tourism are emerging, and the role of innovation and creativity in tourism is increasingly apparent. YXHMC combines the advantages of the tourism specialty, adapts to the requirements of integrated development of culture and tourism, focuses on the tourism innovation field, promote various kinds of creative innovation competitions to create a innovation \& entrepreneurship soil combining the practical problems of tourism industry with the needs of innovation \& entrepreneurship to lay the foundation for the future career development of students. Teachers widely collect information of all kinds of competitions and do a good job in organizing and guiding competitions. They are encouraged to merge their research expertise with 
theoretical knowledge and practical application in the teaching process of professional courses, and to guide students to finish research reports, project plans, entrepreneurship plans, etc. As a result, the students' ability of innovation \& entrepreneurship has been improved quickly. The student teams won the second and third prizes in the final of the Fourth National College Students' Tourism Creativity Competition of Mobile Internet \&Tourism Creativity, and the first prize in the Final of the first Sichuan College Students' Educational Tourism Product Design Competition, etc. in 2018.

\subsubsection{Three Area Linkage to Promote Students' Entrepreneurial Practice}

YXHMC established the university science and technology park in April 2015 according to the entrepreneurship policy of Pidu district government and the guidance of Venture Tianfu and Action Plan of Pidu. The park is the only service-oriented university science and technology park with culture $\&$ tourism as its main feature in the western region, jointly built by the government, enterprises and college. The professional management and enterprise operation are carried out in park with reference to the Three area linkage includes Pidu district, YXHMC campus and park. The park is divided into two area outside and inside college. The park outside is located in Jingrong town, covering an area of 4000 square meters, which is mainly used to incubate alumni projects. The park inside consists of innovation \& entrepreneurship studios, clubs, which are mainly used to incubate projects of college students, covering an area of 3000 square meters.

The Park manages registered student companies and student innovation projects in different regions, provides professional training and guidance, and intensifies the maximum effect of intelligence cost through the tutor system and entrepreneurship support mode. At present, there are 25 innovation and entrepreneurship mentors in total, including 8 industry mentors and 17 professional mentors. The industry experts and business mentors are invited to park to carry out publicity activities from time to time, constantly stimulate students' awareness of innovation \& entrepreneurship, and the students' innovative thinking are sublimated substantially. Chengdu 20 Cultural Communication Co., Ltd., established by students majoring in Tourism, has rapidly expanded its business under the guidance of its tutor after entering the park. In view of the current upsurge of educational tourism, it has developed educational tourism curriculum design and tutors training, etc., cooperating with tourist attractions and museums, and has achieved good business income.

\subsubsection{Multidimensional Interact and Link the Education Space Inside and Outside the College}

The opinions of the State Council on Promoting the Reform and Development of Tourism and the 515 Strategy for Tourism Development require strengthening the cultivation of research-oriented, innovative, practical, international and composite talents, to promote the transformation, upgrading and sustainable development of tourism. YXHMC has incorporated the basic courses of entrepreneurship into the compulsory courses since 2016. The Department of tourism management has set up two credit entrepreneurial characteristic management courses, and has also incorporated entrepreneurship into the students' cultivation education management system. At present, the department of tourism management has a total of 5 innovation \& entrepreneurship mentors. Through courses such as Entrepreneurship Foundation, SYB Training, etc., students' innovation \& entrepreneurship ability in the field of culture and tourism is gradually cultivated and improved. YXHMC has achieved good results by combining the internal and external space through the establishment of the mode of complementary advantages and resource sharing.

\subsubsection{Linking with Local Governments}

Under the background of integrated development of culture and tourism, YXHMC has determined the concept of integrated development of industry and education based on local, industry-oriented, relying on enterprises and serving regions. YXHMC actively undertakes government cooperation projects, actively serves and integrates into regional economic and social development, and supports high-quality integrated development and sustainable innovation capacity of culture and tourism. YXHMC has established close cooperation with Chengdu Tourism Bureau, Sichuan Provincial Department of culture and tourism, and the tourism administrative departments of district (city) and county. The Provincial Tourism Development Commission (now Sichuan Provincial Department of 
culture and Tourism) established four regional tourism poverty alleviation promotion centers in 2016 based on the program of Sichuan Provincial Tourism Poverty Alleviation Leading Group, entrusted colleges to carry out the research, planning, training, guidance and evaluation of regional tourism poverty alleviation. YXHMC undertook the projects in Qinba mountain and Wumeng mountain area, the comprehensive ability of teachers and students has been greatly trained in the projects. In June 2017, Sichuan Provincial Tourism Development Commission highly affirmed the projects, and placed high hopes on the development of tourism specialty and the training of senior tourism management talents for local areas.

\subsubsection{Linking with Industrial Organizations}

YXHMC has established extensive cooperation mechanism with Sichuan provincial tourism association, travel agency association, self-driving camp association, and Chengdu tourism association, etc. to jointly cultivate application-oriented tourism professionals. There are Sichuan provincial university experimental teaching demonstration center (tourism and hotel management professional experimental teaching demonstration center), Sichuan local college talents training model creation experimental area (tourism and hotel management professional diversified application talents training model innovation experimental area) and the national western tourism professional training demonstration unit, etc. The industry institutions provide a good platform for the practical teaching, assist in enriching the teaching content, improve the innovation \& entrepreneurship practice level of students, and enhance the efficiency of tourism sspecialty education.

\subsubsection{Linking with Student Associations}

Student associations are not only an important way of extracurricular practice, but also an important carrier of promoting students' innovation \& entrepreneurship ability. In the interactive development of innovation \& entrepreneurship education and tourism specialty education, YXHMC always committed to innovate community's organizational activity. The establishment of characteristic entrepreneurship practice platform and the improvement of service guarantee mechanism improve students' innovation and entrepreneurship ability ultimately. On the basis of the two-level platform of the college and department, the student association organizations in tourism department have been continuously developed and improved. The theme community activities such as tour guide style competition, color running festival, exhibition planning competition and intangible cultural heritage festival, etc. improved the students' practical ability greatly, and the theoretical knowledge has been better combined with the culture and tourism development.

\section{Literature References}

The ministry of education of the people's Republic of China launched the National Innovation and Entrepreneurship Training Program for College Students in 2007. Since then, colleges all over the country have been exploring and practicing the reform of talent training mode, strengthening the training of innovation \& entrepreneurship ability. Enhancing the innovation ability \& entrepreneurship ability on the basis of innovation are the core of cultivating high-level innovative talents to meet the needs of the construction of an innovative country. By November 7, 2019, 15259 items have been found in CNKI with the keyword of college students' innovation and entrepreneurship. Among them, the number of higher educations in the discipline distribution is the largest, reaching 12456, indicating that the main battlefield for the cultivation of college students' innovation and entrepreneurship ability is Colleges. From the perspective of time trajectory, the number of articles increased from 155 to 3664 from 2001 to 2018, and the growth rate of documents has accelerated significantly after 2010. This is closely related to the relevant policies of innovation and entrepreneurship, such as The Opinions of the Ministry of Education on Vigorously Promoting the Innovation and Entrepreneurship Education and Students' Independent Entrepreneurship in Colleges and Universities. Then, the implementation of preferential policies to encourage the innovation and entrepreneurship of college students are matching the emphasis on the cultivation of practical ability in the education and teaching reform of colleges, and achieved good results. 
The practical characteristics of tourism specialty education determine its essential relationship with innovation and entrepreneurship education, so scholars in the study of tourism specialty education always involve in the cultivation of students' innovation ability more or less, mainly around the following four issues, and put forward practical suggestions. First, the old specialty education mode and the limited learning space in a single classroom lead to the lack of students' awareness of innovation ability (Ni, 2019; Huang, 2019; Zhang, 2013). Second, tourism specialty education construction lacks characteristics and professional characteristics (Lai \& Ma, 2019; Yang, 2013). Third, the specialty education objectives are not clear, and there is a lack of keen ability to capture emerging tourism formats ( $\mathrm{Li} \& \mathrm{Tu}, 2019$ ). Fourth, the curriculum is not reasonable, and the cultivation of students' ability does not match the requirements of tourism enterprises (Zhang \&Ma, 2019; Luo \&Shi, 2019; Wang \&Cheng, 2018; Guo \&Le, 2012).

How to improve the ability of innovation and entrepreneurship of students majoring in tourism is the focus of tourism specialty education, to better adapt to the high-quality development of culture and tourism. In the Chinese literature of CNKI, 21 pieces of literature were listed by key word of innovation and entrepreneurship of college students majoring in tourism. From the perspective of student level, there are more literature on the path or method of innovation \& entrepreneurship education in higher vocational colleges (Qiao, 2019; Zhang, 2019, Cao \& Yue, etc., 2018). Undergraduate colleges and universities mainly focus on the construction of innovation and entrepreneurship system for students, including characteristic courses (Peng, 2019), teaching mode (Wei, 2016), incubation base (Song, 2017), etc. It reflects the difference between the goal orientation and specification design of tourism specialty education. The former pays more attention to practical operation, strengthens the training process and ability expression, so that students can actively adapt to the needs of the construction and development of an innovative country and become high-quality innovators in the field of culture and tourism. The latter is obviously more concerned about the rationality of the specialty education system. By changing the concept of teaching, reforming the specialty education mode, combining classroom teaching with business practical, at last cultivate innovative and entrepreneurial talents contribute to the development of culture and tourism.

\section{Summary}

Innovation is not only the power to improve the quality of professionals training, but also the requirement of the current integration of culture and tourism for tourism specialty education. The cultivation of students' innovation and entrepreneurship ability is one of the goals of higher education. The integration development of culture and tourism calls for innovation to drive new vitality. It is urgent for tourism specialty education to focus on cultivation of innovation ability, improve the comprehensive quality. The practicable way to build a three-dimensional system of ubiquitous learning space consist of breaking through the traditional mode and build creative and innovative teaching space, integrating resources to build innovation $\&$ entrepreneurship resources sharing space and multidimensional interaction and link the education space inside and outside the college. The interactive development of innovation and entrepreneurship education and tourism specialty education is realized in the process of ubiquitous learning space, consist of three aspects: promoting education reform, improving working mechanism and building service system, thus the new ecology of college students' innovation and entrepreneurship is constructed to cultivate a large number of innovation \& entrepreneurship talents for culture and tourism industry. The application oriented to the needs, and the innovation oriented to the actual problems of the integration of culture and tourism are emphasized, which effectively improves the cultivation of high-quality application-oriented talents and cultivates a group of cultural and tourism entrepreneurs with comprehensive and systematic knowledge acquisition. 


\section{Acknowledgements}

Project supported by 2019 Ministry of Culture and Tourism of the People's Republic of China Double-qualified Teachers Training Program (WLRCS2019-041), The National Social Science Fund of China (No.19BJY210).

\section{References}

[1]. Cao Chunli, Yue Le, Pan yingying, et al. Research on the path of integrating innovation and entrepreneurship education into higher vocational tourism management personnel training. Theoretical Observation. (2018) No. 03, p. 146-148.

[2]. Guo peicai, Le Shanghong. A study on the current employment situation and countermeasures of tourism majors in newly established universities. Journal of Huaihua University. Vol. 31(2012) No. 03, p. 110-112.

[3]. Huang Leyan. Study on the training mode of tourism talents in higher vocational education from the perspective of holistic tourism. Shanxi Agricultural Economics. (2019) No. 13, p. 120.

[4]. Lai Zhijie. Exploration and practice of talent training mode of tourism specialty based on deep optimization, integration of production and education, and collaborative education. Education Modernization. Vol. 6(2019) No. 61, p. 11-14.

[5]. Li Xiang, Tu Yan. Exploration of innovative personnel training mode of tourism management major in higher vocational education-taking Guangdong province as an example. Economist. (2019) No. 09, p. 163-164+244.

[6]. Luo Jinhua, Shi Yu. Exploration on optimization of application-oriented undergraduate talent training system of tourism management. Journal of Changchun Normal University. Vol. 38(2019) No. 02, p. 126-131.

[7]. Ma Yong, Yang Yang. Research on the construction and optimization of national characteristic professional points of tourism management based on the adjustment of new professional catalogue. Contemporary Continuing Education. Vol. 31(2013) No. 05, p. 68-70.

[8]. Ni Shanshan. Exploration and research on the training mode of three creation tourism management professionals. Journal of Shanxi Economic Management Cadre College. Vol. 27 (2019) No. 03, p. 4-7.

[9]. Peng Zhen, Wang Liguo. Study on the characteristic curriculum system of innovation and entrepreneurship education of tourism management major in local agricultural and forestry colleges and universities-taking Jiangxi Agricultural University as an example. Science and Education Guide. (2019) No. 05, p. 45-47.

[10]. Qiao Xiaoqian. Research on the cultivation path of innovation and entrepreneurship education for tourism majors in higher vocational education from the perspective of rural revitalization-a case study of Jiangsu agricultural and forestry polytechnic. Journal of Liaoning Agricultural Polytechnic. (2019) No. 04, p. 39-42.

[11]. Song Li. Research on the innovation of curriculum teaching mode based on the achievements of rural entrepreneurship of college students-taking tourism management as an example. Quality Education in the West. Vol. 3(2017) No. 22, p. 198-199.

[12]. Wang Xiaofeng, Cheng Wei. Exploring the optimization of curriculum system of tourism management under the new normal of tourism-the perspective of constructivism. Journal of Capital Normal University: Natural Science Edition. Vol. 39(2018) No.01, p. 65-71. 
[13]. Wang Yuchan. Interpretation and development path of Internet + education. Journal of Changchun Normal University. Vol. 36(2017) No. 03, p. 150-153.

[14]. Wei Ting. Building the innovation and entrepreneurship system of college students based on the business incubation base-taking the tourism management major of Chongqing second normal university as an example. Intelligence. (2016) No. 34, p. 64-65.

[15]. Zhang Heqing, Ma Jing. Research on the integration of tourism management major and innovation and entrepreneurship education in colleges and universities. Cooperative Economy and Technology. (2019) No. 19, p. 96-97.

[16]. Zhang June. An analysis of the practical teaching system of management major in applied universities. Heilongjiang Higher Education Research. Vol. 31(2013) No. 02, p. 166-169.

[17]. Zhang Yingying. Practical innovation of entrepreneurship training mode for tourism management majors in higher vocational colleges. Journal of Jiamusi Vocational College. (2019) No. 02 , p. $288+290$. 